\title{
Interdisciplinary Curriculum Development for Digital Library Education
}

\author{
Seungwon Yang ${ }^{1}$, Edward A. Fox ${ }^{1}$, \\ Barbara M. Wildemuth ${ }^{2}$, Jeffrey Pomerantz ${ }^{2}$, and Sanghee $\mathrm{Oh}^{2}$ \\ ${ }^{1}$ Department of Computer Science, Virginia Tech, \\ Blacksburg, VA 24061 U.S.A. \\ +1 540-231-5113 \\ \{seungwon, fox\}@vt. edu \\ ${ }^{2}$ School of Information and Library Science, University of North Carolina - Chapel Hill, \\ Chapel Hill, NC 27599-3360 U.S.A. \\ +1 919-962-8366 \\ wildemails.unc.edu \\ \{jpom, shoh\}@email.unc.edu
}

\begin{abstract}
The Virginia Tech (VT) Department of Computer Science (CS) and the University of North Carolina at Chapel Hill (UNC-CH) School of Information and Library Science (LIS) are developing curricular materials for digital library (DL) education, appropriate for the CS and LIS communities. Educational modules will be designed, based on input from the project advisory board, Computing Curriculum 2001, the 5S framework, and workshop discussions. These modules will be evaluated, first through expert inspection and, second, through field testing. We are identifying and refining module definitions and scopes, collecting related resources, developing a module template, and creating example modules. These will be presented at the conference. The developed curriculum should contribute to producing well-balanced digital librarians who will graduate from CS or LIS programs.
\end{abstract}

Keywords: digital library, curriculum, 5S framework, education, CC2001.

\section{Introduction}

Contemporary human societies are inundated with enormous amounts of information. To address the need for high quality, organized information, many digital libraries (DLs) have been developed. However, there has not been much focus on education for people who design and administer DLs compared to the investment in DLs. To solve this problem, Virginia Tech's Department of Computer Science (VT CS) and the University of North Carolina at Chapel Hill School of Information and Library Science (UNC SILS) have taken the first steps toward developing an interdisciplinary curriculum and collection of related resources for DL education [1]. Through a three-year project, ${ }^{1}$ we will define, develop, and test educational modules, guided by experts, the

\footnotetext{
${ }^{1}$ Funded by NSF Grant IIS-0535057 to VT and IIS-0535060 to UNC-CH for 2006-2008.

S. Sugimoto et al. (Eds.): ICADL 2006, LNCS 4312, pp. 61-70, 2006.

(c) Springer-Verlag Berlin Heidelberg 2006
} 
Computing Curriculum 2001 [3, 4], the 5S framework [5, 6, 7], and analysis of existing DL course syllabi. Each module will include lesson plans, concept maps, exercises, demos, online resources, and a recommended reading list for both instructors and students. We encourage reuse, e.g., one- and two-semester DL courses can be based on selected modules.

Computer scientists working on DL areas tend to focus on the system side, while librarians, who administer digital libraries, generally put more emphasis on the service aspect of DLs. We expect our project will aid both CS and LIS students and instructors, as well as reduce the communication gap between the communities.

\section{Foundations for Curriculum Development}

To develop digital library modules and courses, standing on a solid foundation, we will follow a standard curriculum design model of analysis, design/development, and evaluation [2]. Currently, we are in the initial 'design' phase, identifying DL education modules and lessons. We have obtained expert guidance, since good module design requires a natural flow between modules and thorough understanding of DL courseware. Once the resulting modules are developed, they will be evaluated, first through inspection by experts in the area covered by the module, as well as by Ph.D. students attending JCDL doctoral consortia. Then, after revision based on the expert reviews, the modules will be evaluated as they are used to teach DL courses in CS and LIS.

To encourage active participation of DL researchers, we have presented papers in the $9^{\text {th }}$ International Symposium on Electronic Theses and Dissertations, and the $6^{\text {th }}$ ACM/IEEE-CS Joint Conference on Digital Libraries. In addition, we introduced the project in the workshop, 'Developing a Digital Libraries Education Program,' held right after the JCDL '06 conference. The organizers of the workshop plan to have a conference on DL education in 2007, and will involve our team in that activity.

As a theoretical foundation for our work, we have adopted the $5 \mathrm{~S}$ framework [5, 6, 7], developed in the Digital Library Research Laboratory at Virginia Tech. The label " $5 \mathrm{~S}$ " refers to the five elements of this framework:

- Streams: all types of contents as well as communications and flows over networks, or into sensors, or sense perceptions (e.g., text, video, audio)

- Structures: organizational schemes including data structures, databases, and knowledge representations (e.g., catalog, metadata, hypertext )

- Spaces: 2D and 3D interfaces, GIS data, representations of documents and queries (e.g., interfaces, storage, vector/probabilistic/feature spaces)

- Scenarios: system states and events; also representations of situations of use by human users or machine processes, yielding services or transformations of data (e.g., searching, browsing, recommending)

- Societies: both software "service managers" and generic "actors", including (collaborating) human "users" (e.g., service managers, teachers, learners)

$5 \mathrm{~S}$ gives a formal framework (see $[5,7]$ ) and a checklist for digital library development. We can say that a digital library has all the necessary components if all of the $\mathrm{Ss}$ are considered in its specification [6]. This $5 \mathrm{~S}$ framework also can be used to 
describe the nature of and relationships among the DL modules in this project. Each DL module component can be explained by one or multiple Ss. The 5S framework helps us ensure that we have precise definitions of all key ideas in the modules, and that all important concepts in the DL field are covered.

In addition to the 5S framework, we used the ACM / IEEE-CS Computing Curriculum $2001[3,4]$ to design the basic structure of the module development. It covers a variety of areas, including Information Management. 'IM14. Digital libraries [elective]' explains topics and learning objectives regarding digital library education.

Since DL is a young and evolving field, and since education is primarily a human endeavor, we are engaging DL researchers and practitioners in designing the DL curricular framework. Currently we have an advisory board that includes colleagues from VT (10 people, mostly from Computer Science), UNC (13 people, mostly from Library and Information Science), and several other institutions. At two advisory board meetings already held (one at VT and one in conjunction with JCDL '06), we discussed module development, and received suggestions regarding resource preparation. Some instructors agreed to participate in module content development, providing access to their class materials, or to use their classes as part of the later evaluation in the field.

\section{Digital Library Module Development}

Initially 19 DL modules (components) have been identified [17]. They have been revised further to reflect the discussions at advisory board meetings. For example, some modules were integrated into others and new modules were added to ensure coverage of costing and economics, project management, and DL evaluation. Currently, we have designed a module template, and are developing the lessons in each module.

Fig. 1 shows the set of DL modules as well as one possible way of grouping them into a two-semester DL sequence. The benefit of this 'modular' design is that instructors can use the modules to create a course (or course sequence or program - or can make enhancements to existing courses) to exactly match their purposes. Instructors might create a course based on a single module if it contains enough resources. They also can plug a single or multiple modules into their current courses. For example, "Module 3-b: multimedia" can be extended into a course including various aspects of multimedia resource creation, management, and evaluation. (A draft design of module 3-b is explained in Section 3.3.) "Module 1: Overview" and "Module 10: DL Education \& Research" can be used together as an introductory lecture in any type of course that deals with the theoretical and technical issues of DLs.

\subsection{Digital Library Modules}

In some cases, multiple modules will form a DL course, while in other cases one or more courses might deal with a particular module. For example, in LIS programs, there might be several courses related to services. A typical LIS program might have distinct courses to cover modules 7, Services; 7-a, Information needs, relevance, evaluation, effectiveness; 7-b, Search and search strategy, information seeking behavior, 


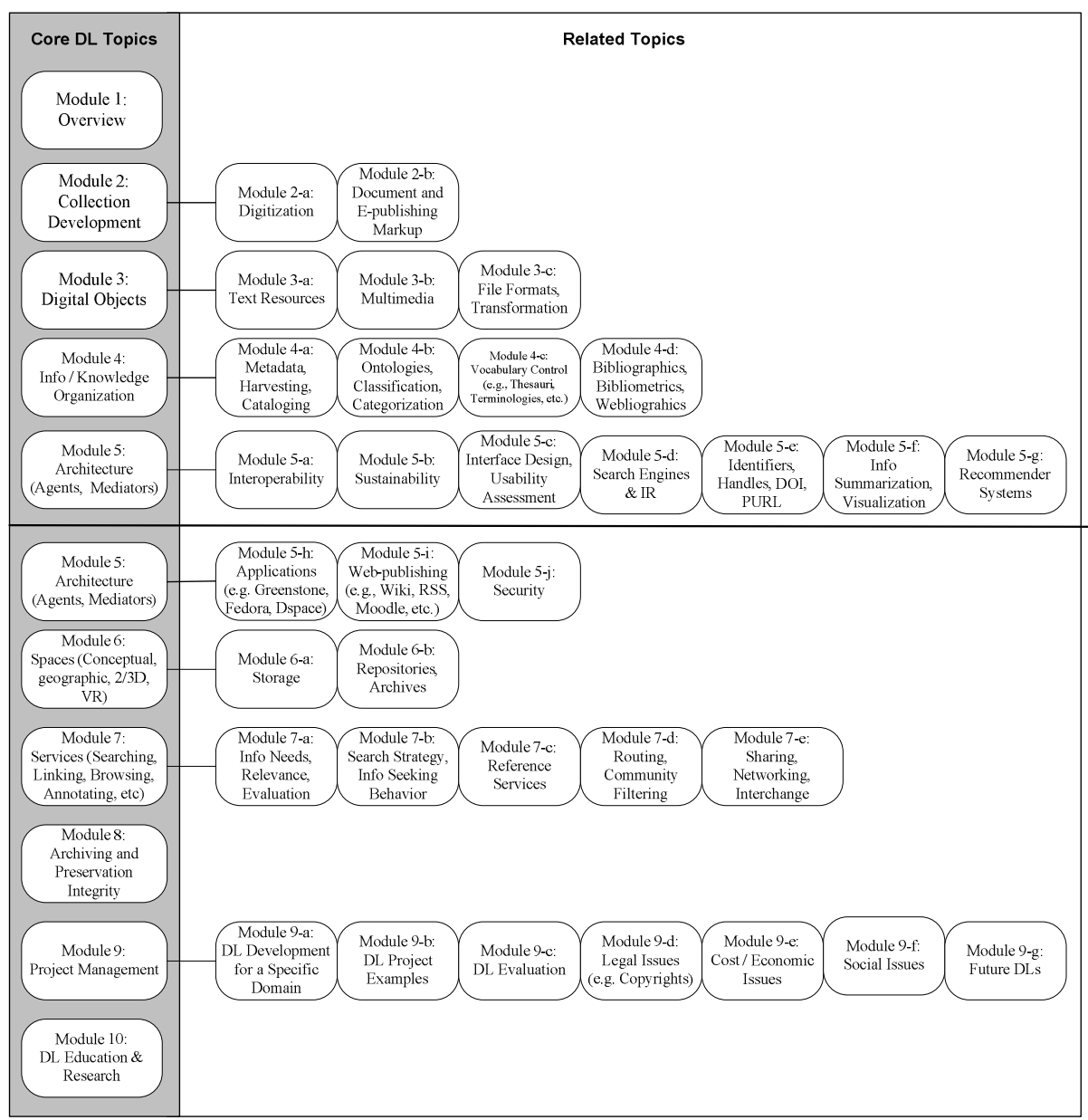

Fig. 1. Digital library modules in a two-semester DL sequence

user modeling, feedback; and 5-f, Information summarization, visualization. In CS, these topics might be covered in courses on information retrieval, human-computer interaction, and information visualization. Regarding DL architecture, for an LIS program the focus might be on DL design and management [15]. If the course is for CS students, the architecture module might focus on technical aspects of DLs. Thus, different versions of course modules may be needed for CS or LIS programs, and coverage might vary in accord with the level of students' knowledge.

To ensure this type of design, modules should be highly flexible and designed in detail. Each module should be decomposable into individual topics and their corresponding resources, so that some topics could be skipped or studied in different order. Clearly there will be revisions as we develop the content of each module and obtain feedback from experts and instructors. We will work to achieve wide coverage as well as balance between theory and practice, with various example digital libraries, and activities that involve use of many of the popular DL management systems. 


\subsection{Module Template Development}

A module template was developed based on the educational experience of the research team, CC2001 [3, 4], and other resources [11, 12, 13]. The latest version of the template can be viewed online at http://curric.dlib.vt.edu/wiki/index.php/Module template.

The current template design is as follows.

1. Module name

2. Level of effort required (in-class and out-of-class time required for students)

3. Learning objectives

4. Relationships with other modules (flow between modules)

5. $5 \mathrm{~S}$ characteristics of the module

6. Prerequisite knowledge required (completion optional)

7. Introductory remedial instruction (completion optional; intended to address the prerequisite knowledge/skills required)

8. Resources (including all the resources in the 'Body of knowledge' section)

9. Body of knowledge (Theory + Practice):

Topics might be skipped or studied in different orders

For each topic:

Theories and background knowledge of the topic

Learning activities

Presentation slides

Interactive demo

Resources

- Textbooks (one or multiple chapters might be assigned)

- Reference papers (relevant parts might be marked with SI tool [14])

- Advanced reading

Worksheets

10. Concept maps (created by students)

11. Exercises / Learning activities

12. Evaluation of learning outcomes

13. Glossary

14. Useful links

\subsection{Module Preparation}

The aim of module content development is to prepare high-quality study materials such as textbooks, reference papers, interactive demos, tutorials, and exercises (for evaluating students' understanding). There is more than one way to do this. Several advisory board experts expressed an interest in developing module examples with their class materials. Another way is to use publicly-available class materials. For example, we developed module 3-b (draft) based on Wake Forest University's 'Digital Media' curriculum materials [11]. These materials are based on work supported by the National Science Foundation. ${ }^{2}$

\footnotetext{
${ }^{2}$ NSF grants DUE-0127280 and DUE-0340969.
} 
To provide study materials in good quality and quantity, we have been collecting and analyzing digital library course syllabi. We collected syllabi from DELOS member institutions in Europe (see Table 1) and retrieved resources such as textbooks, reference papers, online tutorials, software, and other documents (see Table 2).

Table 1. Selected DELOS member institutions with DL-related courses, and their resources listed $(\mathrm{B}=$ textbooks, reference books; $\mathrm{P}=$ reference papers, conference proceeding papers; $\mathrm{O}$ $=$ online tutorials, articles)

\begin{tabular}{|l|l|l|l|l|l|}
\hline Country & University/Institution & Course Title & B & P & O \\
\hline Austria & $\begin{array}{l}\text { Inst. for Info. Systems and } \\
\text { Computer Media-IICM }\end{array}$ & $\begin{array}{l}\text { Multimedia Information Sys- } \\
\text { tems 2 }\end{array}$ & 0 & 0 & 59 \\
\hline & & Info. Visualisation & 22 & 4 & 4 \\
\hline & Vienna Univ. of Technology & Info. Visualisierung & 7 & 0 & 0 \\
\hline $\begin{array}{l}\text { Czech } \\
\text { Republic }\end{array}$ & Masaryk University of Brno & Informatics Colloquium & 1 & 0 & 0 \\
\hline Germany & $\begin{array}{l}\text { Max-Planck Institut für } \\
\text { Informatik }\end{array}$ & $\begin{array}{l}\text { Information Retrieval and Data } \\
\text { Mining WS 05/06 }\end{array}$ & 18 & 0 & 0 \\
\hline Norway & $\begin{array}{l}\text { Norwegian Univ. of Science } \\
\text { and Technology }\end{array}$ & Information Retrieval & 1 & 0 & 0 \\
\hline
\end{tabular}

Table 2. Selected textbooks and reference books from the resources in Table 1

\begin{tabular}{|l|l|l|}
\hline Topic & Title & Authors \\
\hline Digital Library & From Gutenberg to Global Digital Libraries & Borgman, C. \\
\hline Information Retrieval & $\begin{array}{l}\text { Data Mining: Practical Machine Learning Tools and } \\
\text { Techniques }\end{array}$ & $\begin{array}{l}\text { Ian H. Witten, } \\
\text { Eibe Frank }\end{array}$ \\
\hline Archiving & $\begin{array}{l}\text { Preserving Digital Information: Report of the Task } \\
\text { Force on Archiving of Digital Information }\end{array}$ & Waters, D. et al. \\
\hline $\begin{array}{l}\text { Compression/ } \\
\text { Indexing }\end{array}$ & $\begin{array}{l}\text { Managing Gigabytes: Compressing and Indexing } \\
\text { Documents and Images }\end{array}$ & Ian H. Witten \\
\hline $\begin{array}{l}\text { Database/ } \\
\text { Multimedia }\end{array}$ & Multimedia Database Management Systems & G. Lu \\
\hline $\begin{array}{l}\text { Information Visuali- } \\
\text { zation }\end{array}$ & $\begin{array}{l}\text { Information Visualization in Data Mining and Knowl- } \\
\text { edge Discovery }\end{array}$ & Fayyad et al. \\
\hline
\end{tabular}

\subsection{Literature and Syllabi Analyses}

We also have analyzed published literature on DLs and readings assigned in courses on DLs. We used two corpora for the analysis of published literature: the complete runs of ACM Conference on Digital Libraries, JCDL, and D-Lib Magazine (Pomerantz et al., 2006). This analysis has identified that the greatest number of papers have been published on the topic of DL services and architecture, both in the conferences and in D-Lib. These results demonstrate that there are significant similarities within the literature on digital library across different venues. There are, however, shifts in topical coverage over the years.

For the analysis of course readings, we identified all materials assigned in DL courses in Library and Information Science programs accredited by the American Library Association (Pomerantz et al., in press). This analysis has identified the most 
frequently-assigned authors, books, journal articles, and journal titles in these courses. Additionally, like the analysis of published literature on DLs, this reading list analysis has identified that the greatest number of readings are assigned on the topics of project management and architecture. We are currently working on a similar analysis of reading lists from DL courses in Computer Science programs.

\subsection{Example Modules (Draft)}

While the DL modules are still in the early stages of development, a few examples may illustrate our conception of the finished modules. Fig. 2 shows a portion of the 'Body of Knowledge' for module 3-b: Multimedia, hypertext, and information access. It is based on Wake Forest University's work, "Digital Media Curriculum Development." The complete version can be viewed at http://curric.dlib.vt.edu/wiki/index. php/Module_3b.

\section{Digital Audio Processing}

- $\quad$ Pretest (grade does not count)

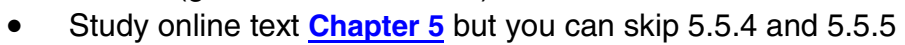

- Carry out activities

1. Interactive tutorial on audio dithering but note on the first question, there is a typo in that they want 64536 instead of the correct value, 65536.

2. Worksheet on audio dithering, where you should turn in the Matlab log, but only do Exercises 1,2,3,4 and Question 1,2, and 6. Also, note the typo for Question 1 where "O" should be "Exercise 2."

3. Worksheet on digital audio file size and file transfer time

4. Interactive tutorial on non-linear quantization and mu-law encoding

5. Worksheet on non-linear quantization and mu-law encoding

- Posttest (grade counts to demonstrate level of mastery)

Fig. 2. A portion of 'Body of Knowledge' section in module 10

In order to understand the topic, 'Digital Audio Processing,' students select the link and read some online text (in this case, chapter 5). They follow steps in the interactive tutorial created with Shockwave (see Fig. 3). Then they can check their level of understanding, solving the problems in worksheets. A score may be assigned to individual worksheets by the inlstructor. In this type of module design, an instructor remains as an 'advisor' or a 'helper' as students study materials themselves.

Module 7-a, Information needs, relevance, evaluation/effectiveness, provides a different type of example (see Fig. 4). The complete module 7-a is at http://curric.dlib. vt.edu/wiki/index.php/Module_7a. Instead of using interactive tutorials or online book chapters, a selected list of reference papers are used (we are preparing this resource collection), including papers on different theoretical models of information seeking written by Wilson, Belkin and Vickery, Belkin, and Taylor. These and additional readings can be assigned to students and/or used by instructors in their preparation for teaching the module. The 'Outline of knowledge' closely follows the content of the 


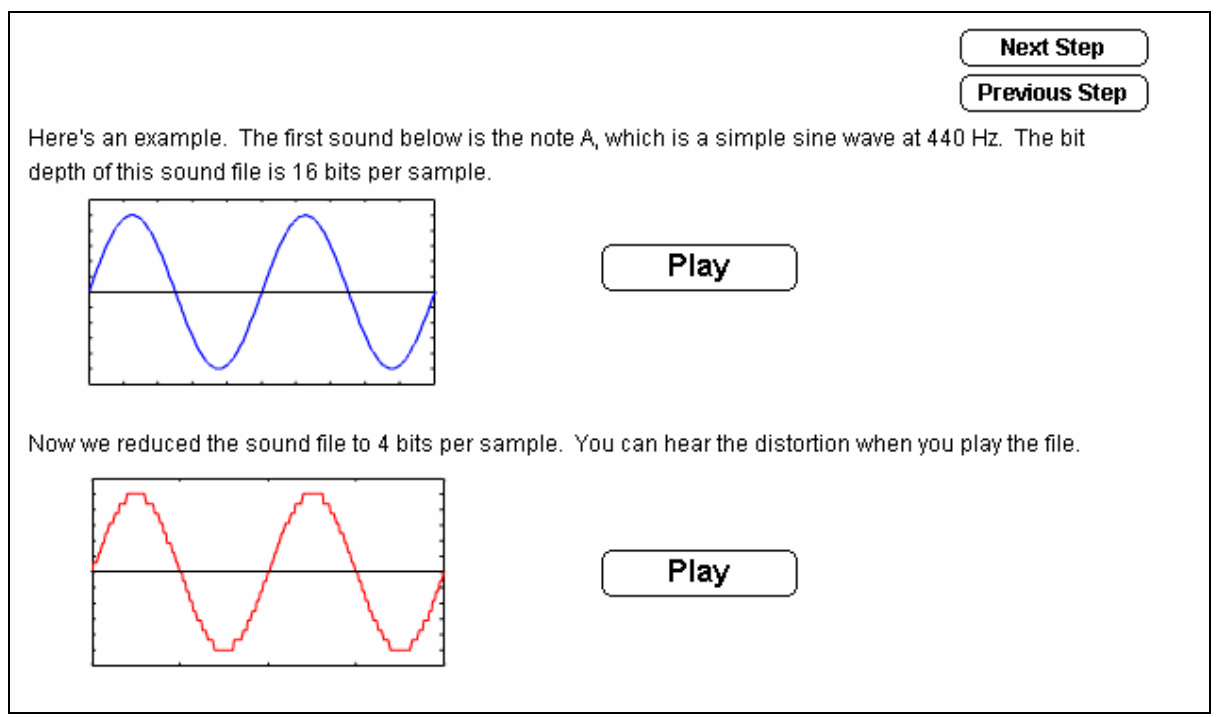

Fig. 3. An example of interactive tutorial, 'Audio Dithering'

Wilson, T. D. (1997). Information behaviour: An interdisciplinary perspective. Information Processing \& Management, 33(4), 551-572.

Yuan, X.-J., Belkin, N. J., \& Kim, J.-Y. (2002). The relationship between ASK and relevance criteria. Proceedings of SIGIR 2002, 359-360.

- c. Outline of knowledge to be covered

\section{WILSON'S MODEL OF INFORMATION BEHAVIORS}

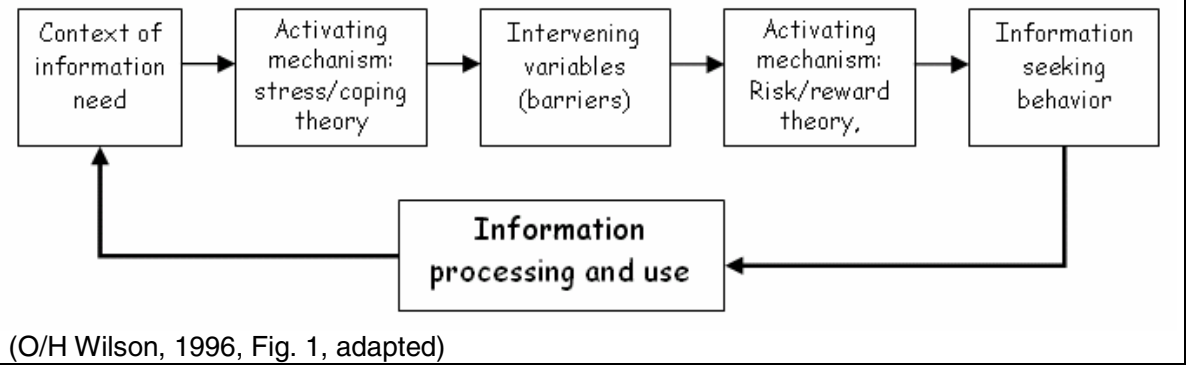

Fig. 4. A portion of 'Body of Knowledge' section in module 7-a

readings, and can be used as the basis for a lecture based on the given outline. Fig. 5 shows a 'Learning activity' within this module, in which students are asked to discuss the introduced topics in pairs. 
Discussion activity: Personal experiences of an information need

To immediately follow the review of Wilson's generalized model of information behavior

Students in the class should be formed into pairs. In each pair, one student will interview the other. (This process should later be repeated, reversing roles.) The person being interviewed should be asked to recall a recent experience of having an information need. The interviewer should ask about the content of the information need, the context in which it arose, and the process through which it was pursued (successfully or unsuccessfully). The pair should then evaluate what was learned about this example of an information need and see if Wilson's model fully describes the process. Were there aspects of the information-seeking episode that are not covered in Wilson's model? Are there aspects of Wilson's model that did not occur during this information-seeking episode?

Fig. 5. A sample learning activity from module 14

\section{Conclusion and Future Work}

The collaborative VT-UNC DL curriculum development project is in the first of its three years, and module design is well underway, supported by the $5 \mathrm{~S}$ framework and an analysis of CC 2001 and existing DL course syllabi. It is our hope that the international DL community will become involved in this interdisciplinary effort, and that its result will be improvement in the education of DL professionals.

\section{References}

1. Collaborative Research: Curriculum Development for Digital Library Education, 2006. Website URL is http://curric.dlib.vt.edu/wiki

2. Kent L. Gustafson and Robert Maribe Branch: Survey of Instructional Development Models ( $3^{\text {rd }}$ ed.). Syracuse University, Syracuse, New York (1997)

3. CC2001, "Computing Curricula 2001 (Web Site)," vol. 2004: ACM and IEEE-CS, 2001. http://www.computer.org/education/cc2001

4. CC2001, "Computing Curricula 2001: Computer Science (IEEE Computer Society and Association for Computing Machinery Joint Task Force on Computing Curricula)," Journal on Educational Resources in Computing (JERIC), vol. 1, 2001. http://doi.acm.org/ $10.1145 / 384274.384275$

5. M. A. Gonçalves, "Streams, Structures, Spaces, Scenarios, and Societies (5S): A Formal Digital Library Framework and Its Applications," Computer Science Doctoral Dissertation. Blacksburg, VA: Virginia Tech, 2004, 161 pages. http://scholar.lib.vt.edu/theses/ available/etd-12052004-135923/unrestricted/MarcosDissertation.pdf

6. M. A. Gonçalves and E. A. Fox, "5SL - A Language for Declarative Specification and Generation of Digital Libraries," in Proc. JCDL'2002, Second ACM / IEEE-CS Joint Conference on Digital Libraries, July 14-18, G. Marchionini, Ed. Portland, Oregon, USA: ACM, 2002, pp. 263-272. 
7. M. Gonçalves, E. Fox, L. Watson, and N. Kipp, "Streams, Structures, Spaces, Scenarios, Societies (5S): A Formal Model for Digital Libraries," ACM Transactions on Information Systems, vol. 22, pp. 270-312, 2004.

8. H. Suleman and E. A. Fox, "A Framework for Building Open Digital Libraries," D-Lib Magazine, vol. 7, 2001. http://www.dlib.org/dlib/december01/suleman/12suleman.html

9. H. Suleman, E. A. Fox, and M. Abrams, "Building Quality into a Digital Library," in Proceedings of the Fifth ACM Conference on Digital Libraries: DL '00, June 2-7, 2000, San Antonio, TX. New York: ACM Press, 2000.

10. Q. Zhu, "5SGraph: A Modeling Tool for Digital Libraries," Department of Computer Science MS thesis. Blacksburg: Virginia Tech, 2002. http://scholar.lib.vt.edu/theses/available/ etd-11272002-21053

11. Yue-Ling Wong, Jennifer Burg, and Leah McCoy, "Integrated Digital Media Curriculum Development Project" Supported by the National Science Foundation under Grant No. DUE-0340969, from Jan 2004 - Dec 2006. The project homepage URL is http://digitalmedia.wfu.edu/project/digital-media-curriculum-development/textbased-index.html

12. Ze-Nian Li and Mark S. Drew, 2006, "Fundamentals of Multimedia" at http://www.cs. sfu.ca/mmbook/

13. Multimedia Systems course website, Department of Computer Science at University of Victoria, British Columbia, Canada, 2006. URL: http://www.csc.uvic.ca/courses/spring 2004/csc/461-561.html

14. The Superimposed Project at Virginia Tech, Blacksburg, VA, 2006. URL: http://si.dlib.vt. edu/

15. Youngok Choi and Edie Rasmussen, "What Do Digital Librarians Do?" in Proceedings of the Sixth ACM/IEEE-CS Joint Conference on Digital Libraries: JCDL '06, June 11-15, 2006, Chapel Hill, NC. USA: ACM, pp. 187-188.

16. Yongqing Ma, Warwick Clegg and Ann O'Brien, "Digital Library Education: The Current Status," in Proceedings of the Sixth ACM/IEEE-CS Joint Conference on Digital Libraries: JCDL '06, June 11-15, 2006, Chapel Hill, NC. USA: ACM, pp. 165-174.

17. Pomerantz, J., Wildemuth, B., Fox, E. A., \& Yang, S. (2006). Curriculum Development for igital Libraries. In Proceedings of the 6th ACM/IEEE-CS Joint Conference on Digital Libraries (pp. 175-184). New York: Association for Computing Machinery.

18. Pomerantz, J., Oh, S., Yang, S., Fox, E. A., \& Wildemuth, B. (in press). The Core: Digital Library Education in Library and Information Science Programs. D-Lib Magazine. 